Micronutrient Deficiencies in the First Months of Life 
Nestlé Nutrition Workshop Series

Pediatric Program, Vol. 52

\section{Micronutrient Deficiencies in the First Months of Life}

Editors

François M. Delange, Brussels, Belgium Keith P. West, Jr., Baltimore, Md., USA

25 figures and 45 tables, 2003 


\section{Nestec Ltd., 55 Avenue Nestlé, CH-1800 Vevey (Switzerland) S. Karger AG, P.O. Box, CH-4009 Basel (Switzerland) www.karger.com}

(C) 2003 Nestec Ltd., Vevey (Switzerland) and S. Karger AG, Basel (Switzerland). All rights reserved. This book is protected by copyright. No part of it may be reproduced, stored in a retrieval system, or transmitted, in any form or by any means, electronic, mechanical, photocopying, or recording, or otherwise, without the written permission of the publisher.

Printed in Switzerland on acid-free paper by Reinhardt Druck, Basel

ISBN 3-8055-7559-9

ISSN 0742-2806

\section{Library of Congress Cataloging-in-Publication Data}

Nestlé Nutrition Workshop (52nd : 2002 : Dubayy, United Arab Emirates)

Micronutrient deficiencies in the first months of life / editors, François M. Delange, Keith

P. West.

p. ; cm. - (Nestlé Nutrition workshop series ; v. 52. Paediatric Programme)

Includes bibliographical references and index.

ISBN 3-8055-7559-9 (hard cover ; alk. paper)

1. Trace element deficiency diseases in children-Congresses. 2. Nutrition disorders in infants-Congresses. 3. Trace elements in nutrition-Congresses. 4.

Infants-Nutrition-Congresses. I. Delange, F. II. West, Keith P. III. Title. IV. Nestlé

Nutrition workshop series ; v. 52. V. Nestlé Nutrition workshop series. Paediatric

Programme.

[DNLM: 1. Deficiency Diseases-Infant-Congresses. 2.

Micronutrients-deficiency-Infant-Congresses. WD 105 N468m 2003]

RJ399.T7N37 2002

$618.92^{\prime} 39-\mathrm{dc} 21$

2003050633

The material contained in this volume was submitted as previously unpublished material, except in the instances in which credit has been given to the source from which some of the illustrative material was derived.

Great care has been taken to maintain the accuracy of the information contained in the volume. However, neither Nestec Ltd. nor S. Karger AG can be held responsible for errors or for any consequences arising from the use of the information contained herein. 


\section{Contents}

VII Preface

IX Foreword

XI Contributors

1 Assessment of Micronutrient Status in Mothers and Young Infants

Bates, C.J. (Cambridge)

35 Setting Dietary Reference Intakes for Micronutrients for Healthy North American Infants: A Process of Trials and Errors

Young, V.R. (Cambridge, Mass.)

55 Assuring Micronutrient Adequacy in the Diets of Young Infants

Allen, L.H.; Graham, J.M. (Davis, Calif.)

89 Iodine Deficiency Disorders in Mothers and Infants Delange, F.M. (Brussels)

103 Public Health Impact of Preventing Vitamin A Deficiency in the First Six Months of Life

West, K.P. Jr. (Baltimore, Md.)

129 Does Iron Deficiency Cause Low Birth Weight, Prematurity, Anemia, and Mortality in Early Infancy?

Beard, J.L. (University Park, Pa.) 
143 Preventing Zinc Deficiency in Early Infancy: Impact on Morbidity, Growth and Mortality

Sazawal, S.; Malik, P. (Baltimore, Md.)

165 Effect of Selenium and Vitamin E Status on Host Defense and Resistance to Infection

Meydani, S.N.; Chung, H.; Han, S.N. (Boston, Mass.)

181 Early Infant Vitamin K Deficiency: Extent, Health

Consequences and Approaches to Prophylaxis

Shearer, M.J. (London); Zhang, H.-F. (Shijiazhuang)

209 Effect of Maternal Micronutrient Supplementation on Newborn Size and Infant Health and Survival

Christian, P. (Baltimore, Md.)

231 Special Micronutrient Concerns in Premature Infants: Implications for Enteral and Parenteral Feeding Zlotkin, S. (Toronto)

245 Micronutrient Interactions on Risk of Infantile Anemia: Going beyond Iron Alone!

Davidsson, L. (Rüschlikon)

265 Rickets due to Maternal and Infant Micronutrient Deficiencies Pettifor, J.M. (Johannesburg)

279 Micronutrients and Child Health in the Presence of HIV Infection

Kupka, R.; Fawzi, W. (Boston, Mass.)

309 Reducing Risks of Birth Defects with Periconceptional Micronutrient Supplementation

Czeizel, A.E. (Budapest)

327 Effects of Micronutrients during Pregnancy and Early Infancy on Mental and Psychomotor Development

Verhoef, H. (Wageningen); West, C.E. (Wageningen/Nijmegen); Bleichrodt, N.; Dekker, P.H. (Amsterdam); Born, M.P. (Rotterdam)

359 Conclusions

363 Subject Index 


\section{Preface}

Micronutrient deficiencies in the first six months of life are often underevaluated in the context and priorities of global malnutrition because they are hard to define and detect, and their effects may be subtle or even visible only later in life when health consequences may be irreversible. Although increased attention has rightly been given in recent years to micronutrient deficiencies during early childhood, pregnancy and lactation, there remains a relative lack of evidence about the prevalence, health consequences and causes of early infantile micronutrient deficiencies across vast, still undernourished populations in the world. The 52nd Nestlé Nutrition Workshop held in Dubai, United Arab Emirates in October 2002, sought to fill this gap in knowledge and expose research priorities by convening distinguished scientists from all over the world to address this critical area of early human nutrition. Formal presentations were enhanced by vivid discussions by a particularly competent and motivated audience.

The present volume reviews current knowledge on different steps that need to be taken to identify, prevent and treat micronutrient deficiencies in the first six months of life: quite logically, it starts by exploring the new Dietary Reference Intakes, as they were recently derived with respect to micronutrients for a healthy North American infant population, along with expert primers on assessing micronutrient status and assuring dietary micronutrient adequacy in mothers and their young infants. The volume presents separate state-of-the-art reviews on the etiology, pathogenesis, epidemiology, clinical aspects, prevention and treatment of key trace element and vitamin deficiencies such as iodine, iron, zinc, selenium, and vitamins A, $\mathrm{D}$ and $\mathrm{K}$ at this early age in life. It also begins to reveal complex micronutrient interactions within the maternal-infant dyad and their implications for neonatal health and infant survival. Unique challenges facing clinicians in maintaining adequate micronutrient status of preterm infants are presented, as are the effects of micronutrient deficiencies and their prevention on 
immune competence, resistance to major infections such as HIV, risk of birth defects and on neurointellectual development.

As always in good science, this workshop replied to some questions but raised many others as both the frontiers of knowledge and horizons for research in this vital area of human nutrition were exposed. Thus, we trust that the content of this volume both informs the nutrition and pediatric communities on the 'state of the art' in this area, while serving to stimulate further research on the prevalence and health implications of micronutrient deficiencies in the first months of life.

K. P. West Jr. and F. M. Delange 


\section{Foreword}

It is sometimes difficult to assess the micronutrient status and recommendations for micronutrients as well as their appropriate application in young infants. For this 52nd Nestlé Nutrition Workshop, which took place in October 2002 in Dubai, the topic 'Micronutrient Deficiencies in the First Months of Life' was chosen. It was not only the deficiency of individual minerals, trace elements and vitamins such as iodine, iron, zinc, selenium, vitamin A, E and K per se that we were interested in, but more importantly the impact these deficiencies have upon public health, growth, morbidity and mortality. Furthermore, we wanted to know what preventive measures, starting even during pregnancy, may exist. In order to answer these and other questions we brought together the knowledge of various experts in different fields in order to better understand the pathogenesis of and the preventive as well as therapeutic implications for diseases such as birth defects, rickets, hypothyroidism, anemia, xerophthalmia, bleeding tendencies, and disturbed psychomotor development.

I would like to thank the two chairmen, Prof. François Delange and Prof. Keith West, who are well-known experts in this field, for putting the program together and inviting as speakers the opinion leaders in the field of micronutrients in health and various disease conditions. Scientists invited from 27 countries contributed to the discussions that are published in this book. Dr. Maged Iskander and his team from Nestlé Middle East provided all the logistic support in order that the participants gain an appreciation of Arabic hospitality. Dr. Denis Barclay, from the Nutrition Strategic Business Division in Vevey, Switzerland, was responsible for the scientific coordination. His cooperation with the chairpersons was essential for the success of this workshop.

Prof. Wolf Endres, $M D$

Vice-President

Nestec Ltd., Vevey, Switzerland 


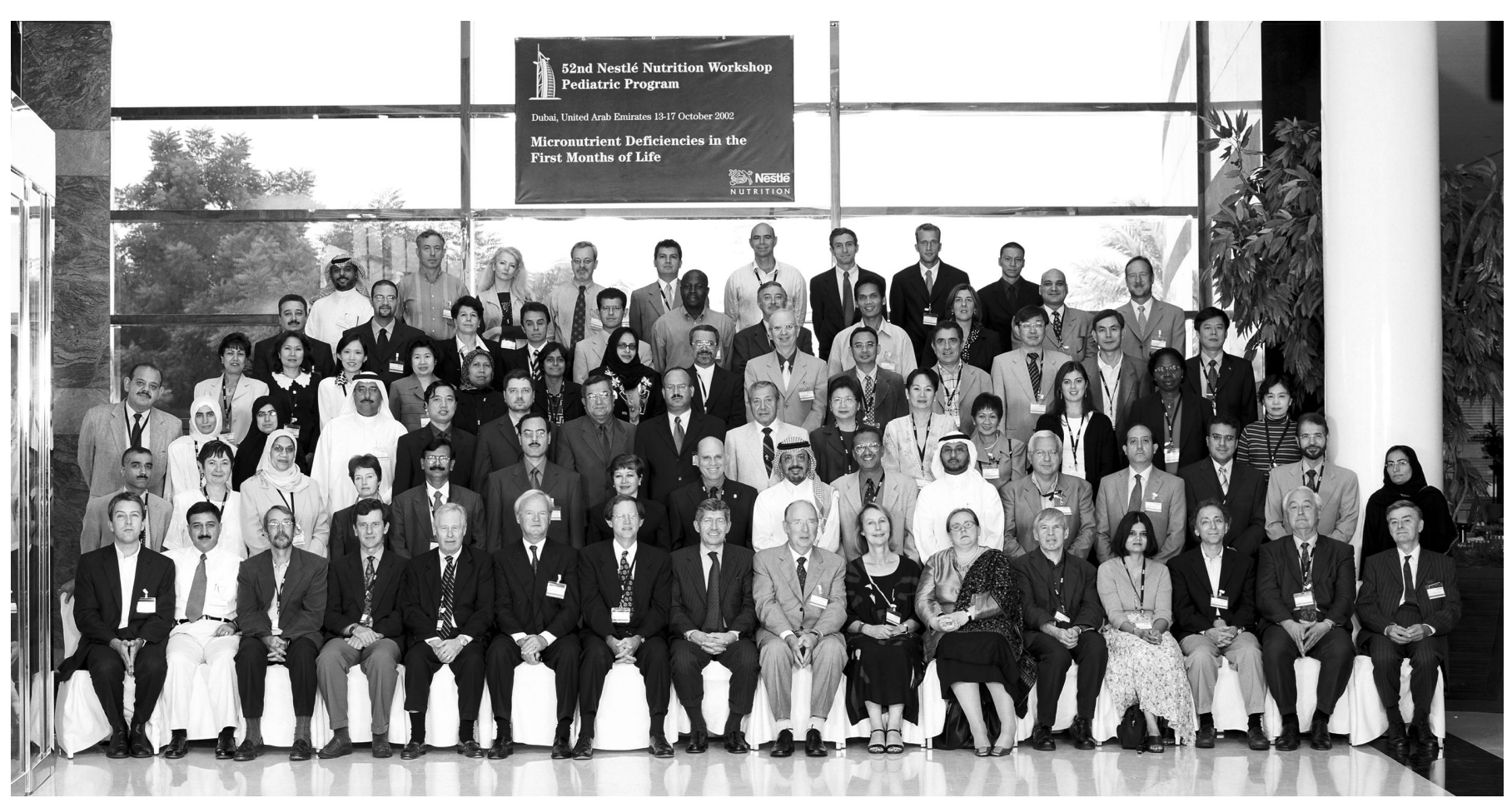

52nd Nestlé Nutrition Workshop Pediatric Program

Dubai, October 13-17, 2002 


\section{Contributors}

\section{Chairpersons, Speakers and Moderators}

\section{Prof. Lindsay H. Allen}

UC Davis Nutrition Department

Faculty

3135 Meyer Hall

University of California

One Shields Avenue

Davis, CA 95616-8669

USA

Tel. +1 5307525920

Fax +1 5307528966

E-Mail lhallen@ucdavis.edu

\section{Dr. Chris J. Bates}

MRC Human Nutrition Research Elsie Widdowson Laboratory

Fulbourn Road

Cambridge CB1 9NL

UK

Tel. +44 1223426356

Fax +44 1223437515

E-Mail Chris.Bates@

mrc-hnr.cam.ac.uk

\section{Prof. John L. Beard}

College of Health and Human

Development

Penn State University

125 S. Henderson Building
University Park, PA 16802-0001

USA

Tel. +1 8148632917

Fax +1 8148636103

E-Mail jbeard@psu.edu

\section{Dr. Parul Christian}

Bloomberg School of Public Health

Center for Human Nutrition

Room 2041, 615 N. Wolfe St.

Baltimore, MD 21205

USA

Tel. +1 4109551188

Fax +1 4109550196

E-Mail pchristi@jhsph.edu

\section{Dr. Andrew E. Czeizel}

Department of Human Genetics and Teratology

National Institute of Hygiene

Budapest

Hungary

Tel. +3612731913

Fax +36 12731914

E-Mail czeizel@interware.hu 


\section{Dr. Lena Davidsson}

Swiss Federal Institute of Technology (ETH)

Laboratory for Human Nutrition

Institute of Food Science

PO Box 474

CH-8803 Rüschlikon

Switzerland

Tel. +4117045703

Fax +41 17045710

E-Mail lena.davidsson@

ilw.agrl.ethz.ch

\section{Prof. François M. Delange}

International Council for Control of Iodine Deficiency Disorders (ICCIDD)

Av. de la Fauconnerie 153

B-1170 Brussels

Belgium

Tel. +32 26758543

Fax +32 26751898

E-Mail fdelange@ulb.ac.be

\section{Dr. Wafaie Fawzi}

Harvard School of Public Health

Department of Nutrition

Building II, Room 329A

655 Huntington Avenue

Boston, MA 02115

USA

Tel. +1 6174322086

Fax +16174322435

E-Mail mina@hsph.harvard.edu

\section{Dr. Simin N. Meydani}

USDA/HNRC at Tufts University

711 Washington Street

Boston, MA 02111

USA

Tel. +1 6175563129

Fax +16175563224

E-Mail smeydani@hnrc.tufts.edu

\section{Prof. John M. Pettifor}

Baragwanath Hospital

Department of Paediatrics

PO Bertsham 2013

South Africa

Tel. +27119331530

Fax +27119389074

E-Mail 092jmpe@chiron.wits.ac.za

\section{Dr. Sunil Sazawal}

Center for Micronutrient Research M-30

Lajpat Nagar - II

New Delhi 110024

India

Tel. +91116921676

Fax +91116927078

E-Mail ssazawal@jhsph.edu

\section{Dr. Martin J. Shearer}

St. Thomas' Hospital

The Haemophilia Reference Centre

Vitamin K Research \& Diagnostic

Unit

London SE1 7EH

UK

Tel. +44 2079289292 ext. 2939/3788

Fax +44 2074013125

E-Mail martin.shearer@kcl.ac.uk

\section{Dr. Hans Verhoef}

Division of Human Nutrition and

Epidemiology

Wageningen University

P.O. Box 8129

NL-6700 EV Wageningen

Tel. + 31317484317

Fax + 31317484342

E-Mail Hans.Verhoef@wur.nl

\section{Prof. Keith P. West, Jr.}

Johns Hopkins University

School of Hygiene and Public Health

Dept. of International Health

Division of Human Nutrition and

Center for Human Nutrition

615 N. Wolfe Street

Baltimore, MD 21205-2179

USA

Tel. +1 4109552061

Fax +1 4109550196

E-Mail kwest@jhsph.edu

\section{Prof. Vernon R. Young}

Massachusetts Institute of

Technology

Lab Human Nutrition,

Room E17-434

School of Science

77 Massachusetts Avenue

Cambridge, MA 02139 
USA

Tel. +1 6172535801

Fax +1 6172539658

E-Mail vryoung@mit.edu

\section{Prof. Stanley Zlotkin}

University of Toronto

Dept. of Paediatrics and Nutritional Sciences

Centre for International Health
Division of Gastroenterology and Nutrition

Hospital for Sick Children, Toronto, Ont.

Canada

Tel. +1 4168136171

Fax +1 4168134972

E-Mail szlotkin@sickkids.ca

\section{Nestlé Participants}

Ms. Roberta Portes / Brazil

Mr. Hatem El Kalyoubi / Egypt

Dr. Louis-Dominique Van Egroo /

France

Mr. Elias Papadopoulos / Greece

Ms. Lenetta Aguirre / Philippines

Dr. Olga Netrebenko / Russia

Dr. Denis Barclay / Switzerland

Prof. Wolf Endres / Switzerland

Mr. Sanjay Sehgal / Switzerland

Ms. Marie-Christine Secretin /

Switzerland

Mr. Alexander J. Cantacuzène /

United Arab Emirates

Mr. George Salem / United Arab

Emirates

Ms. Sara Jackson / United Arab

Emirates

Dr. Maged Iskander / United Arab

Emirates

Mr. Rami Safi / United Arab Emirates

\section{Invited attendees}

Prof. Francisco Martinez / Brazil

Prof. Liwen Chang / China

Prof. Chao Chen / China

Prof. Hanqiang Chen / China

Prof. Xindong Xue / China

Dr. Marija Radonic / Croatia

Dr. Inés Zambrano / Ecuador

Prof. Ahmed Amr Abbassy / Egypt

Prof. Mohamad Badawi / Egypt

Prof. Moustafa El Saied / Egypt

Prof. Moustafa El Hodhod / Egypt

Dr. Alexandra Papdopoulou / Greece

Prof. Konstantinos Samaras / Greece

Dr. Ioannis Sigalas / Greece

Dr. Kin Sing Ip / Hong Kong

Prof. Mummulla Indra Shekhar Rao /

India

Dr. Dasril Daud / Indonesia

Dr. Eric Gultom / Indonesia

Dr. Bidasari Lubis / Indonesia

Dr. Samir Al Faouri / Jordan

Dr. Fredrick Were / Kenya

Dr. Mohammed al Jasser / Kingdom of

Saudi Arabia

Dr. Khayria Mousa / Kingdom of Saudi

Arabia

Dr. Omar Saa'da / Kingdom of Saudi

Arabia

Dr. Abdullah al Shehri / Kingdom of

Saudi Arabia

Dr. Sami Wali / Kingdom of Saudi

Arabia

Dr. Mohammad al Yamani / Kingdom

of Saudi Arabia

Dr. Abdallah al Zabin / Kingdom of

Saudi Arabia

Dr. Woo-Tack Kim / Korea

Prof. Sang Lak Lee / Korea 


\section{Invited attendees (continued)}

Prof. Mazen al Essa / Kuwait Prof. Wafaa al Qabandi / Kuwait Prof. Adib Moukarzel / Lebanon Dr. Nabil Mounla / Lebanon Prof. Robert Sacy / Lebanon Dr. Nazeli Hamzah / Malaysia Dr. Prema Subramaniam / Malaysia

Dr. Alberto Garcia Aranda / Mexico Dr. Ricardo Alejandro Corona Alfaro / Mexico

Dr. Solange Heller / Mexico

Dr. Alfredo Larrosa Haro / Mexico

Dr. Jesus Nares / Mexico

Dr. Amina Saad / Morocco

Prof. Kikelomo Osinusi / Nigeria

Dr. Bassam Abu Libdeh / Palestine

Dr. Corazon Barba / Philippines

Dr. Lourdes Paulino / Philippines
Prof. Nafisa Al Jae'fi / Republic of Yemen

Prof. Elena Lukushkina / Russia

Prof. Zakia Al Lamki / Sultanate of Oman

Dr. Hazem Attar / Syria

Dr. Mahmoud Bozo / Syria

Prof. Munzer El Haddadin / Syria

Prof. Pipop Jirapinyo / Thailand

Dr. Umaporn Suthutvoravut /

Thailand

Dr. Shahraban Abdallah / United Arab

Emirates

Prof. Youssef Abdel Razzak / United

Arab Emirates

Dr. Yasser Al Nuaimi / United Arab

Emirates

Dr. Badriya al Awar / United Arab

Emirates

Prof. Adekunle Dawoodo / United

Arab Emirates 


\title{
ADDENDUM
}

\author{
Moderators
}

\section{Prof. Abdulrahman Saleh} Al Frayh

King Khaled University Hospital

College of Medicine

Department of Pediatrics

P.O. Box 2925

Riyadh 11461

Saudi Arabia

Tel. + +9661 4671507

Fax + +96614671570

E-Mail alfrayh@yahoo.com

\section{Dr. Abdulla Al Khayatt}

Al Wasl Hospital

P.O. Box 9115

Dubai, United Arab Emirates

Tel. ++97143062165

Fax + +971 43241628

E-Mail aialkhayat@dohms.gov.ae

\section{Prof. Khaled Al Saeid}

Kuwait University

P.O. Box 5969

Safat 13060

Kuwait

Tel. ++9654838760

Fax + +9654838756

E-Mail khaledalsaeid@hotmail.com

\section{Prof. F. Azizi}

Shaheed Beheshti University of Medical Sciences

Endocrine Research Centre

Eveen, Tehran

IR Iran

Tel. ++98 212403909

Fax ++98212402463

E-Mail azizi@erc-iran.com 


\section{Invited attendees}

Prof. Francisco Martinez / Brazil Prof. Liwen Chang / China

Prof. Chao Chen / China Prof. Hanqiang Chen / China Prof. Xindong Xue / China Dr. Marija Radonic / Croatia Dr. Inés Zambrano / Ecuador Prof. Ahmed Amr Abbassy / Egypt Prof. Mohamad Badawi / Egypt Prof. Moustafa El Saied / Egypt Prof. Moustafa El Hodhod / Egypt Dr. Alexandra Papadopoulou / Greece Prof. Konstantinos Samaras / Greece Dr. Ioannis Sigalas / Greece Dr. Kin Sing Ip / Hong Kong Prof. Mummulla Indra Shekhar Rao / India

Dr. Dasril Daud / Indonesia

Dr. Eric Gultom / Indonesia

Dr. Bidasari Lubis / Indonesia

Dr. Samir Al Faouri / Jordan

Dr. Fredrick Were / Kenya

Dr. Mohammed Al Jasser / Kingdom of Saudi Arabia

Dr. Khayria Mousa / Kingdom of Saudi Arabia

Dr. Omar Saa'da / Kingdom of Saudi Arabia

Dr. Abdullah Al Shehri / Kingdom of Saudi Arabia

Dr. Sami Wali / Kingdom of Saudi Arabia

Dr. Mohammad Al Yamani / Kingdom of Saudi Arabia

Dr. Khaled Al Hathol / Kingdom of

Saudi Arabia

Dr. Woo-Taek Kim / Korea

Prof. Sang Lak Lee / Korea

Prof. Mazen Al Essa / Kuwait

Prof. Wafaa Al Qabandi / Kuwait

Prof. Adib Moukarzel / Lebanon

Dr. Nabil Mounla / Lebanon

Prof. Robert Sacy / Lebanon

Dr. Nazeli Hamzah / Malaysia

Dr. Prema Subramaniam / Malaysia

Dr. Alberto Garcia Aranda / Mexico

Dr. Ricardo Alejandro Corona Alfaro / Mexico
Dr. Solange Heller / Mexico

Dr. Alfredo Larrosa Haro / Mexico

Dr. Amina Saad / Morocco

Prof. Kikelomo Osinusi / Nigeria

Dr. Bassam Abu Libdeh / Palestine

Dr. Corazon Barba / Philippines

Dr. Lourdes Paulino / Philippines

Prof. Nafisa Al Jae'fi / Republic of

Yemen

Prof. Elena Lukushkina / Russia

Prof. Zakia Al Lamki / Sultanate of

Oman

Dr. Hazem Attar / Syria

Dr. Mahmoud Bozo / Syria

Prof. Munzer El Haddadin / Syria

Dr. Narumon Densupsoontorn /

Thailand

Dr. Umaporn Suthutvoravut /

Thailand

Dr. Shahraban Abdallah / United Arab

Emirates

Dr. Badriya Al Awar / United Arab

Emirates

Dr. Yasser Al Nuaimi / United Arab

Emirates

\section{Nestlé Participants}

Ms. Roberta Portes / Brazil

Mr. Hatem El Kalyoubi / Egypt

Dr. Louis-Dominique Van Egroo /

France

Mr. Elias Papadopoulos / Greece

Ms. Lennetta Aguirre / Philippines

Dr. Olga Netrebenko / Russia

Dr. Denis Barclay / Switzerland

Prof. Wolf Endres / Switzerland

Mr. Alexander J. Cantacuzène /

United Arab Emirates

Mr. George Salem / United Arab

Emirates

Ms. Sara Jackson / United Arab

Emirates

Dr. Maged Iskander / United Arab

Emirates

Mr. Rami Safi / United Arab Emirates 